\title{
The value of CHONS isotopic measurements of major compounds as probes of planetary origin, evolution, and habitability
}

\begin{abstract}
Kelly E. Miller ${ }^{1 *}$, Bethany Theiling ${ }^{2}$, Amy E. Hofmann ${ }^{3}$, Julie Castillo-Rogez ${ }^{3}$, Marc Neveu $^{2,4}$, Sona Hosseini ${ }^{3}$, Jessica Barnes ${ }^{5}$, Katherine de Kleer ${ }^{6}$, Thomas J. Barrett $^{7}$, Heather B. Franz ${ }^{2}$, Christopher R. Glein ${ }^{1}$, Christopher H. House ${ }^{8}$, Ryan C. Blase $^{1}$, Mark J. Libardoni ${ }^{1}$, Linda J. Spilker ${ }^{3}$, Mathieu Choukroun ${ }^{3}$, Brian J. Drouin $^{3}$
\end{abstract}

*kmiller@swri.edu, (210)522-2215

With support from:

Conel M. O’D. Alexander ${ }^{9}$, Scott Bolton ${ }^{1}$, Jim Burch ${ }^{1}$, Morgan L. Cable ${ }^{3}$, M. Darby Dyar ${ }^{10}$, Dionysis I. Foustoukos ${ }^{9}$, Katherine H. Freeman ${ }^{8}$, Margaret E. Landis $^{11}$, Dante S. Lauretta ${ }^{5}$, Brian A. Magee ${ }^{12}$, Kathy Mandt ${ }^{13}$, William B. McKinnon ${ }^{14}$, Olivier Mousis ${ }^{15}$, Rebecca Perryman ${ }^{1}$, Lynnae C. Quick ${ }^{2}$, Everett L. Shock $^{16}$, Danielle Wyrick ${ }^{1}$

${ }^{1}$ Southwest Research Institute, San Antonio, TX

${ }^{2}$ NASA Goddard Space Flight Center, Greenbelt, MD

${ }^{3}$ Jet Propulsion Laboratory, California Institute of Technology, Pasadena, CA

${ }^{4}$ University of Maryland College Park, Greenbelt, MD

${ }^{5}$ University of Arizona, Tucson, AZ

${ }^{6}$ California Institute of Technology, Pasadena, CA

${ }^{7}$ The Open University, Milton Keynes, UK

${ }^{8}$ The Pennsylvania State University, University Park, PA

${ }^{9}$ Carnegie Institution of Washington, Washington, DC

${ }^{10}$ Mount Holyoke College, South Hadley, MA

${ }^{11}$ Laboratory for Atmospheric and Space Physics, University of Colorado, Boulder, CO

${ }^{12}$ Southwest Research Institute, Boulder, CO

${ }^{13}$ Johns Hopkins University Applied Physics Laboratory, Laurel, MD

${ }^{14}$ Washington University, Saint Louis, MO

${ }^{15}$ Aix-Marseille Université, Marseille, France

${ }^{16}$ Arizona State University, Tempe, AZ

A portion of this research was carried out at the Jet Propulsion Laboratory, California Institute of Technology, under a contract with the National Aeronautics and Space Administration (80NM0018D0004). 


\section{Executive Summary}

Carbon, hydrogen, oxygen, nitrogen, and sulfur (CHONS) are key ingredients for life, as well as components of volatile compounds that drive geological activity in many environments. CHONS isotopic ratios are a powerful tool for addressing critical questions in planetary science (Table 1). Existing isotopic measurements demonstrate the value of these data for understanding planetary origins and evolution and provide a roadmap for using isotopes to search for biosignatures. To address the science questions outlined in this white paper, we recommend investment in critical technologies (Table 4) that enable isotopic measurements of extraterrestrial materials with high sensitivity, precision, and accuracy, including: (1) Sample preparation, separation, and introduction technologies for direct sampling and returned sample analyses; (2) Mitigation and reduction of contamination, including low-outgassing materials, maintaining spacecraft cleanliness through launch, and lessons learned from current and past missions; (3) Curational and calibration facilities; (4) Laboratory and modeling studies to develop frameworks for the interpretation of mission data. These capabilities will support investigation of possible mission targets that include Mars sample return, Ocean Worlds, the ice giants, comets, Kuiper Belt Objects (KBOs), and inner solar system targets including the Moon, Mercury, and Venus.

Table 1. Isotopic measurements have demonstrated value in addressing high priority science questions. Examples of potential future opportunities for scientific progress are highlighted.

\begin{tabular}{|c|c|c|c|}
\hline Theme & Relevant V\&V Priority Science Questions & Past Isotopic Constraints & Future Opportunities (Traced to Table 4 Targets) \\
\hline \multirow{3}{*}{$\begin{array}{l}\text { (1) Origins / } \\
\text { Building new } \\
\text { worlds }\end{array}$} & $\begin{array}{l}\text { What were the initial stages, conditions, and } \\
\text { processes of solar system formation and the } \\
\text { nature of the interstellar matter that was } \\
\text { incorporated? }\end{array}$ & $\begin{array}{l}\text { - Relationship between meteorites, Earth, } \\
\text { Moon, Mars via three-oxygen isotope map } \\
\text { - Stellar origins of presolar grains via C, O } \\
\text { and } \mathrm{N} \text { isotopes }\end{array}$ & $\begin{array}{l}\cdot(1 \mathrm{~A}) \text { Origin of volatiles at the Moon, Mercury, asteroids, } \\
\text { comets, Mars, and/or the outer solar system via CHONS } \\
\text { isotopes, and especially HON }\end{array}$ \\
\hline & $\begin{array}{l}\text { How did the giant planets and their satellite } \\
\text { systems accrete, and is there evidence that } \\
\text { they migrated to new orbital positions? }\end{array}$ & $\begin{array}{l}\text { - Origin of Titan's atmosphere via } \mathrm{N} \text { isotopes } \\
\text { - Origin and source materials for select } \\
\text { Saturnian satellites via } \mathrm{C} \text { and } \mathrm{H} \text { isotopes } \\
\text { - Hypothesis of different Jovian and } \\
\text { Saturnian volatile reservoirs via } \mathrm{D} / \mathrm{H}\end{array}$ & $\begin{array}{l}\cdot(1 \mathrm{~B}) \text { Nature and origin of } \mathrm{C}, \mathrm{O} \text {, and } \mathrm{N} \text { in giant planets, as } \\
\text { well as noble gases } \\
\text { • (1C) Origin of water in Jovian satellites via } \mathrm{H} \text { and } \mathrm{O} \\
\text { isotopes }\end{array}$ \\
\hline & $\begin{array}{l}\text { What governed the accretion, supply of water, } \\
\text { chemistry, and internal differentiation of the } \\
\text { inner planets and the evolution of their } \\
\text { atmospheres, and what roles did bombardment } \\
\text { by large projectiles play? }\end{array}$ & $\begin{array}{l}\text { - Relationship between water at Mars and } \\
\text { Earth and small bodies via D/H } \\
\text { measurements of comets and carbonaceous } \\
\text { chondrites }\end{array}$ & $\begin{array}{l}\text { - (1D) Nature and origin of } \mathrm{H} \text { and } \mathrm{O} \text { at Venus via } \\
\text { measurements of atmosphere and surface material for } \\
\text { comparison to other inner planets } \\
\text { - (1E) Relationship between Main Belt Comets and inner } \\
\text { solar system water via } \mathrm{H} \text { and } \mathrm{O} \text { isotopes }\end{array}$ \\
\hline \multirow{2}{*}{$\begin{array}{l}\text { (2) } \\
\text { Evolution/ } \\
\text { Workings of } \\
\text { solar } \\
\text { systems }\end{array}$} & $\begin{array}{l}\text { Can understanding the roles of physics, } \\
\text { chemistry, geology, and dynamics in driving } \\
\text { planetary atmospheres and climates lead to a } \\
\text { better understanding of climate change on } \\
\text { Earth? }\end{array}$ & $\begin{array}{l}\text { - Cycling of Martian materials between } \\
\text { surface and atmosphere via CHONS } \\
\text { isotopic measurements, including S in } \\
\text { meteorites }\end{array}$ & \multirow{2}{*}{$\begin{array}{l}\text { - (2A) Constrain atmosphere-surface interactions and } \\
\text { volatile cycling at Mercury, Venus, Mars, lo, Titan, Triton, } \\
\text { and Pluto via CHONS isotopic measurements for } \\
\text { comparative planetology }\end{array}$} \\
\hline & $\begin{array}{l}\text { How have the myriad chemical and physical } \\
\text { processes that shaped the solar system } \\
\text { operated, interacted, and evolved over time? }\end{array}$ & $\begin{array}{l}\text { - Comparisons of isotopic ratios in different } \\
\text { solar system materials and bodies to } \\
\text { compare }\end{array}$ & \\
\hline \multirow{3}{*}{$\begin{array}{l}\text { (3) Bio- } \\
\text { signatures / } \\
\text { Planetary } \\
\text { habitats }\end{array}$} & $\begin{array}{l}\text { What were the primordial sources of organic } \\
\text { matter, and where does organic synthesis } \\
\text { continue today? }\end{array}$ & $\begin{array}{l}\text { - Identification of low-temperature origins for } \\
\text { chondritic organics via } \mathrm{H} \text { and } \mathrm{N} \text { isotopes; } \\
\text { relationship between chondritic organics and } \\
\text { carbonates via } \mathrm{C} \text { isotopes }\end{array}$ & $\begin{array}{l}\text { - (3A) Isotopic measurements of organic material on Ceres, } \\
\text { Europa, Titan, Enceladus, Triton, and Pluto and other } \\
\text { Kuiper belt objects }\end{array}$ \\
\hline & $\begin{array}{l}\text { Did Mars or Venus host ancient aqueous } \\
\text { environments conducive to early life, and is } \\
\text { there evidence that life emerged? }\end{array}$ & $\begin{array}{l}\text { - Constraints on evolution of volatile } \\
\text { reservoirs at Mars via } \mathrm{H} \text { and } \mathrm{O} \\
\text { measurements of surface and atmosphere, } \\
\text { and at Venus via } \mathrm{H} \text { isotopic measurements } \\
\text { of atmosphere }\end{array}$ & $\begin{array}{l}\text { - (3B) } \mathrm{H} \text { and } \mathrm{O} \text { isotopic measurements of Venus } \\
\text { atmosphere and surface material } \\
\cdot(3 \mathrm{C}) \mathrm{CHONS} \text { isotopic measurements in organic material } \\
\text { and sulfates/sulfides returned from Mars }\end{array}$ \\
\hline & $\begin{array}{l}\text { Beyond Earth, are there modern habitats } \\
\text { elsewhere in the solar system with necessary } \\
\text { conditions, organic matter, water, energy, and } \\
\text { nutrients to sustain life, and do organisms live } \\
\text { there now? }\end{array}$ & $\begin{array}{l}\text { - Terrestrial framework for } \mathrm{H} \text { and } \mathrm{C} \text { isotopic } \\
\text { characteristics of biotic and abiotic } \\
\text { compounds (including ongoing work) }\end{array}$ & $\begin{array}{l}\text { - (3D) Search for biosignatures on potentially habitable } \\
\text { bodies, including: } \\
\text { • (3D1) Compound-specific isotopic analyses in organic } \\
\text { material from Enceladus' plume } \\
\text { • (3D2) Isotopic ratios in bulk organic material and } \\
\text { inorganic baselines (e.g., Ceres, Europa, Enceladus, Mars) }\end{array}$ \\
\hline
\end{tabular}




\begin{tabular}{|l|l|l|l|}
\hline & & $\begin{array}{l}\cdot(3 \mathrm{D} 3) \text { Measurement of simple molecules with multiple } \\
\text { rare ("clumped") isotopes }\end{array}$ \\
\hline
\end{tabular}

2. Introduction

Measurement of isotopic ratios is an essential tool for identifying the source and evolution of not only geologically and biologically important compounds but also planetary bodies. The mass difference in two isotopes of a given element (e.g., ${ }^{13} \mathrm{C}$ and ${ }^{12} \mathrm{C}$ ) can lead to separation ("isotopic fractionation") between phases, among different compounds, through reaction networks, or via physical processes (Table 2). Measurement of the isotopic ratios of a given compound combined with geological context can therefore provide valuable insight into the compound origins and/or a record of physical, chemical, or biological processes [1].

Table 2. The processes summarized here are important to planetary origins, planetary evolution, and biotic processes because they fractionate isotopes, creating measurable signatures.

\begin{tabular}{|l|l|l|}
\hline Type of fractionation & Relevant processes & Examples of applications/occurrence \\
\hline \multirow{2}{*}{$\begin{array}{l}\text { Mass-dependent } \\
\text { fractionation }\end{array}$} & Equilibrium fractionation & Geothermometer, especially for high temperatures \\
\cline { 2 - 3 } & Distillation processes & Cloud formation or melt crystallization \\
\cline { 2 - 3 } $\begin{array}{l}\text { Mass-independent } \\
\text { fractionation }\end{array}$ & Kinetic processes & Diffusion, evaporation, atmospheric loss to space, enzymatic mediation \\
\hline
\end{tabular}

3. Origins

What were the initial stages, conditions, and processes of solar system formation and the nature of the interstellar matter that was incorporated? Isotopic ratios provide critical information about the early solar system. Application of oxygen isotope ratios to identify mixing of reservoirs as a significant process in the protoplanetary disk may be the most widely used example [2,3]. In addition, $\mathrm{O}, \mathrm{C}$ and $\mathrm{N}$ isotopes in presolar grains have been used to identify the type of star from which the grains formed, and the high ${ }^{2} \mathrm{H} /{ }^{1} \mathrm{H}(\mathrm{D} / \mathrm{H})$ and ${ }^{15} \mathrm{~N} /{ }^{14} \mathrm{~N}$ ratios of chondritic organics are commonly interpreted as evidence for formation at low temperatures. Further work is needed to understand the relationship between primitive isotopic reservoirs such as presolar grains, chondritic organics, and primordial water, and the current distribution of volatiles throughout the solar system. Future measurements of CHONS isotopic ratios in volatiles from the inner and the outer solar system, including sample return from small body populations, are needed to advance understanding of the processes key to solar system formation.

How did the giant planets and their satellite systems accrete, and is there evidence that they migrated to new orbital positions? In the Saturnian system, isotopes constrain conditions both in the subnebula and at the birthplace of Phoebe. Titan's nitrogen isotope ratio differs considerably from solar and predicted cometary $\mathrm{N}_{2}$ ratios, but is similar to $\mathrm{NH}_{3}$ ice in comets [4], consistent with Titan's accretion from materials processed in a warm Saturnian subnebula [5]. However, the $\mathrm{D} / \mathrm{H}$ and ${ }^{13} \mathrm{C} /{ }^{12} \mathrm{C}$ ratios [6] measured at Phoebe suggest that it formed at greater heliocentric distances and/or out of the plane of the protoplanetary disk, where photochemical processing of $\mathrm{CO}_{2}$ fractionated ${ }^{13} \mathrm{C}$ and ${ }^{12} \mathrm{C}$ [7]. Additional insights into the origins of planetary systems are likely to arise from in-situ CHONS isotopic ratios of giant planet atmospheres, as well as their satellites' volatiles.

What governed the accretion, supply of water, chemistry, and internal differentiation of the inner planets and the evolution of their atmospheres, and what roles did bombardment by large projectiles play? The Rosetta mission made isotopic measurements of volatile CHONS (as well as $\mathrm{Xe}, \mathrm{Ar}$, and $\mathrm{Si}$ ) at Comet 67P/Churyumov-Gerasimenko [8]. Notably, the $\mathrm{D} / \mathrm{H}$ ratio for Comet $67 \mathrm{P}$ is 
$\sim 3 \times$ higher than the terrestrial ratio, suggesting that the role of $67 \mathrm{P}-$ like comets in delivering water to Earth may have been small compared to carbonaceous chondrites [9]. However, more data are needed to constrain volatile delivery to the inner solar system as a whole, as well as to determine the primordial relationship between small body source reservoirs. Interpretation of the $\mathrm{D} / \mathrm{H}$ ratio in the Venusian bulk atmosphere - the value of most significant interest for disentangling the history of water abundance and loss at Venus - is hampered in part by potentially conflicting data: Pioneer Venus $\mathrm{D} / \mathrm{H}$ and Venus Express $\mathrm{D} / \mathrm{H}$ differ by a factor of three, although the measurements were made below and above the clouds, respectively [10,11]. High-precision $\mathbf{D} / \mathbf{H}$ measurements throughout the Venusian atmosphere will enable discrimination among hypotheses regarding the volume, flux, timing, altitude-dependence, and processes affecting water (and, hence, the prospects for past habitability) on Venus. Complementary high-precision ${ }^{18} \mathrm{O} /{ }^{16} \mathrm{O}$ measurements of $\mathrm{H}_{2} \mathrm{O}$ or refractory mineral phases [12] could provide additional constraints. Measurement of $\mathrm{D} / \mathrm{H}$ and ${ }^{18} \mathrm{O} /{ }^{16} \mathrm{O}$ in hydrous phases at active asteroids in the main belt will clarify relationships between different small body reservoirs and the source of volatiles in the inner solar system [13].

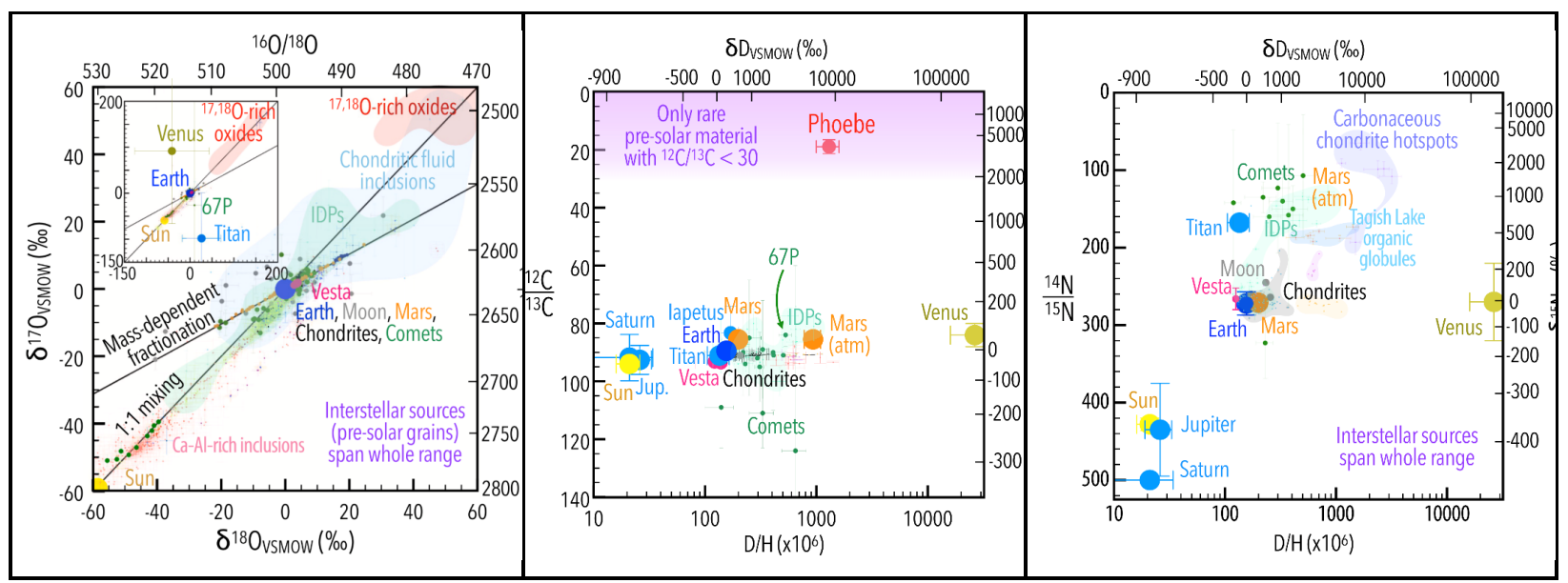

Figure 1. Trends in isotopic "maps" of solar system worlds, such as mixing of reservoirs (bottom left and top right corners of left panel), outliers (Phoebe in middle panel), and gradients (right panel) have helped unravel the origins of the solar system. More subtle trends reveal the imprint of evolutionary processes (e.g. atmospheric escape on Mars and Venus, right panel), including life. Many worlds and materials are still missing from these maps; so is the understanding that could stem from such measurements. Adapted from [7].

\section{Evolution}

Can understanding the roles of physics, chemistry, geology, and dynamics in driving planetary atmospheres and climates lead to a better understanding of climate change on Earth? Comparative planetology provides context for interpretation of planetary climates. Martian isotopic data provide insight into atmospheric loss processes (Fig. 1 right panel). Enriched D/H and ${ }^{15} \mathrm{~N} /{ }^{14} \mathrm{~N}$ ratios in the Martian atmosphere confirm conclusions from ${ }^{38} \mathrm{Ar} /{ }^{36} \mathrm{Ar}$ data that a substantial fraction of Mars' original atmosphere has been lost over time [14-17]. Sequestration as carbonate may also have significantly altered the abundance of atmospheric $\mathrm{CO}_{2}$ and may even have exceeded escape to space during the Hesperian [18]. Future measurement of ${ }^{\mathbf{1 3}} \mathbf{C} /{ }^{\mathbf{1 2}} \mathbf{C}$ in Martian carbonates as a function of age [19] would extend understanding of carbon sinks on hydrologically active bodies beyond Earth. Obtaining any isotopic knowledge on Venus surface materials would begin to constrain the evolution of its climate, providing a third data point for solid planets and insight into Earth's possible far-future. 
How have the myriad chemical and physical processes that shaped the solar system operated, interacted, and evolved over time? Oxygen isotopic analyses of minerals in carbonaceous chondrites have provided strong constraints on their early aqueous alteration. Mass-dependent oxygen isotopic data have been used as a geothermometer [20], while mass-independent trends indicate mixing between the fluid and mineral phases, constraining open vs. closed system alteration [21,22] and time frame. Comparable future isotopic measurements on other planetary bodies and returned samples can provide strong constraints on environmental parameters such as temperature, closed or open system behavior, mixing of different reservoirs [20-22], as well as photochemical processes responsible for mass-independent effects [23-25]. Relevant laboratory data are crucial for accurate interpretation of data acquired from extraterrestrial samples.

\section{Biotic Processes}

On Earth, organisms fractionate isotopes of $\mathrm{H}, \mathrm{C}, \mathrm{N}$, and $\mathrm{S}$ during uptake, cellular development, and metabolism. Large fractionations are observed in $\mathrm{H}, \mathrm{C}, \mathrm{N}$, and $\mathrm{S}$ isotope systems, suggesting that evidence for life could be identified in a planetary system from stable isotope measurements (Fig. 2). Indeed, stable isotopes of carbon and sulfur are often used to support claims of the earliest life on Earth [26], using modern-day observations of biological isotope fractionation. Biological isotope fractionation can be observed in several forms: mineral/rock deposits, organic matter, and trapped or escaping gases.

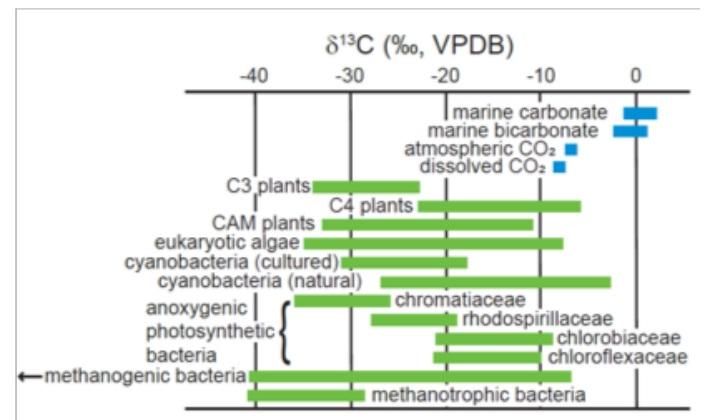

Figure 2. $\delta^{13} C$ for typical inorganic (blue) relative to organic (green) sources demonstrates the characteristic large isotopic fractionation generated by biology. Figure adapted from [28].
It is imperative for astrobiology to understand isotope fractionations for chemosynthetic pathways in varied conditions (e.g., temperature, oxidation state) and how such records could change over time. For example, biotic and abiotic processes lead to different $\mathrm{C}$ but similar $\mathrm{H}$ fractionations in methane [27]. This provides a framework for evaluating methane $\mathrm{C}$ and $\mathrm{H}$ isotopes on Mars or Titan for possible biosignatures, provided such fractionations are understood in specific planetary conditions, such as the effects of Titan's atmospheric chemistry and escape.

The $\mathrm{S}$ isotope system is also often used to describe the modern and ancient influence of sulfate-reducing microbes in anaerobic systems. As seawater sulfate is consumed by modern organisms, the fraction of ${ }^{34} \mathrm{~S}$ in unconsumed sulfate increases relative to ${ }^{32} \mathrm{~S}$ [29] whereas $\mathrm{H}_{2} \mathrm{~S}$ produced by these microbes is depleted in ${ }^{34} \mathrm{~S}$ to an extent controlled by microbial species, sulfate concentration, and rate of respiration [30-32]. Such fractionations have been recorded in sulfate minerals or sulfate bound in the crystal lattice of carbonate minerals, as observed in terrestrial rocks $>2 \mathrm{Ga}[33,34]$, with low $\delta^{13} \mathrm{C}$ in associated minerals suggesting a biological source [35]. Sulfate minerals are thus good targets for biosignature evaluation by in situ and sample return missions.

There are challenges in using isotopic biosignatures. First, all abiogenic mechanisms must be ruled out before an isotopic signature can be accepted as biogenic. For example, the Sample Analysis at Mars (SAM) mass spectrometer on the Mars Science Laboratory (MSL) has measured a range in $\delta^{34} \mathrm{~S}$ of sulfate and sulfide minerals comparable to that produced by 
biological systems on Earth. However, equilibrium fractionation and photochemistry together provide a feasible abiotic source for these observations [36]. Second, the magnitude of metabolic fractionation is affected by the concentration of electron donors and acceptors, the metabolic and burial rates, and the overall biotic productivity. Third, terrestrial microbial ecosystems typically change with depth due to the type and availability of electron acceptors (e.g., $\mathrm{O}_{2}$ or $\mathrm{SO}_{4}{ }^{2-}$ ). Zones of microbes may interact over variable spatial scales, producing complex mixing trends (e.g. Fig. 6 in [37]). Fourth, in situ analysis of organic and mineral samples typically requires significant sample processing. Despite these challenges, biological isotopic trends appear to be predictable, and therefore are prime candidates for biosignatures. Thus, continued advancement of isotope analytical techniques for biosignature detection is crucial.

\section{Advances in Technology and Techniques}

Direct, in situ sampling of planetary environments enables determination of variability in terms of time, space, or both via multiple measurements with moderate sensitivity and high precision. The most common methods include mass spectrometry (MS) and tunable laser spectroscopy (TLS). On Mars, isotopic compositions of atmospheric gases and gases evolved from heated samples have been measured by the SAM instrument suite, which combines MS and TLS, each focusing on different targets for highest precision. For Europa Clipper, the MAss Spectrometer for Planetary EXploration (MASPEX) has high sensitivity and high mass resolution to remove isobaric interferences [38]. In-situ millimeter wave spectroscopy has demonstrated very low mass and power resources, while enabling $<10$ percent level isotopic measurements in a broad range of compounds [39].

Remote sensing via flight and ground-based spectroscopy enables acquisition of a large number of measurements (including surveys) for a wide variety of mission architectures. Submillimeter-wave spectroscopy is a mature technique for isotopic measurements in cometary comae: Rosetta/MIRO measured oxygen isotopologues of $\mathrm{H}_{2} \mathrm{O}$ in the vicinity of 67P [40], Herschel/HIFI measured $\mathrm{O}$ and $\mathrm{H}$ isotopes at 103P from $0.2 \mathrm{AU}$ [41], and SOFIA measured D/H at 46P [42]. The Atmospheric Chemistry Suite (ACS) FTIR has measured martian gases as part of the ExoMars mission [43]. At high enough column densities, the long pathlength enables determination of hard to observe ratios like ${ }^{13} \mathrm{C} /{ }^{12} \mathrm{C}$ and ${ }^{18} \mathrm{O} /{ }^{16} \mathrm{O}$ in $\mathrm{CO}_{2}$. Spatial Heterodyne Spectrometers (SHS) $[44,45]$ allow both direct and remote isotopic measurements. SHS are ideally suited to measuring targeted spectral signals from angularly extended targets such as planetary gases, exospheres and plumes with a small bandpass range from far-UV [46,47] to IR wavelengths [48]. Several SHS-based instruments have flown on sounding rockets [46], and in low-Earth orbit [49,50]. Observations of Titan CO isotopes [51] and $\mathrm{D} / \mathrm{H}$ of water in the Martian atmosphere [52] demonstrate the value of continued application of ground-based observatories to planetary targets.

Laboratory analyses of planetary materials offer high sensitivity and, in some instances, spatial resolution at sub-mm or better scales. Spatially resolved isotopic ratios can be obtained using Secondary Ion Mass Spectrometry (SIMS) or nanoSIMS, providing valuable petrologic context. Nuclear magnetic resonance (NMR) can be performed non-destructively, but has reduced sensitivity overall and does not provide petrologic context. Recent developments in laboratory analysis include position specific isotopic measurements, currently made via NMR [53] or pyrolysis-MS. For a molecule such as $\mathrm{CH}_{3} \mathrm{COOH}$, acetic acid, such measurements can distinguish the carbon isotope ratio for the $\mathrm{CH}_{3}$ position from the $\mathrm{COOH}$ position. Such data show strong promise, but further development is needed to establish rigorous context for 
interpretation, as well as support more sensitive measurements via MS [54]. Other promising techniques include atomic probe tomography (APT), which can spatially resolve isotopic heterogeneity in nanoscale materials such as presolar grains [55].

Table 3. Summary of techniques used for isotopic analyses with current challenges and opportunities for investment in the next decade

\begin{tabular}{|c|c|c|c|c|}
\hline Technique & Unique capabilities & Current challenges & Potential advancements & Impact of Investment \\
\hline $\begin{array}{l}\text { Mass spectrometry } \\
\text { (direct sampling) }\end{array}$ & $\begin{array}{l}\text { - Measurement of broad } \\
\text { range of compounds, } \\
\text { including ability to survey } \\
\text { unknown compounds }\end{array}$ & $\begin{array}{l}\text { - Trade-off between } \\
\text { sensitivity and instrument- } \\
\text { analyte interactions } \\
\text { - Contamination } \\
\text { - Sample prep }\end{array}$ & $\begin{array}{l}\text { - Improved front end separation } \\
\text { and purification techniques (e.g. } \\
\text { single and multi-dimensional GC, } \\
\text { open source) } \\
\text { - Low-outgassing spacecraft } \\
\text { materials }\end{array}$ & $\begin{array}{l}\text { - High precision measurement of trace } \\
\text { isotopologues, including unknown } \\
\text { compounds; measurement of isotopes } \\
\text { in liquid and/or solid phase } \\
\text { compounds; overall decrease in } \\
\text { uncertainty and error }\end{array}$ \\
\hline $\begin{array}{l}\text { Tunable laser } \\
\text { spectroscopy (direct } \\
\text { sampling) }\end{array}$ & \begin{tabular}{|l|} 
- High precision stable \\
isotope ratios in $\mathrm{C}, \mathrm{H}, \mathrm{N}, \mathrm{O}$, \\
$\mathrm{S}$ with low resource \\
envelope
\end{tabular} & $\begin{array}{l}\text { - Form factor for electronics } \\
\text { - Contamination } \\
\text { - Sample prep }\end{array}$ & $\begin{array}{l}\text { - Increase TRL to } 6 \text { for all-digital } \\
\text { miniaturized electronics based on } \\
\text { Zynq chip and for detector array. }\end{array}$ & $\begin{array}{l}\text { - Reduced resource requirements for } \\
\text { measurement of targeted compounds } \\
\text { in situ }\end{array}$ \\
\hline $\begin{array}{l}\text { Spatial Heterodyne } \\
\text { Spectrometer (direct } \\
\text { sampling, remote) }\end{array}$ & $\begin{array}{l}\text { - At-a-distance and near- } \\
\text { field targets }\end{array}$ & $\begin{array}{l}\cdot \text { Relatively little flight } \\
\text { heritage }\end{array}$ & - Maturation of TRL & $\begin{array}{l}\text { - Enhanced ability for surveys of } \\
\text { targeted compounds in extended } \\
\text { sources }\end{array}$ \\
\hline $\begin{array}{l}\text { Submillimeter } \\
\text { Spectroscopy (remote) }\end{array}$ & $\begin{array}{l}\text { - Measurement of broad } \\
\text { range of compounds; } \\
\text { observes from thousands to } \\
\text { millions of km depending on } \\
\text { antenna size and column } \\
\text { density }\end{array}$ & $\begin{array}{l}\text { - High power requirements } \\
\text { - Only a few species can be } \\
\text { measured simultaneously } \\
\text { with one receiver; multiple } \\
\text { channels are needed }\end{array}$ & $\begin{array}{l}\text { - Maturation of low-mass and } \\
\text { power instruments, including } \\
\text { antenna }\end{array}$ & $\begin{array}{l}\text { - Reduced resource requirements for } \\
\text { measurement of targeted compounds } \\
\text { remotely }\end{array}$ \\
\hline $\begin{array}{l}\text { Millimeter Spectroscopy } \\
\text { (in-situ) }\end{array}$ & $\begin{array}{l}\text { - Measurement of broad } \\
\text { range of CHONS } \\
\text { compounds in tenuous } \\
\text { environment; low mass- } \\
\text { low power - low volume }\end{array}$ & $\begin{array}{l}\text { - Recent technique, little } \\
\text { flight heritage }\end{array}$ & $\begin{array}{l}\text { - Maturation of TRL to } 6 \text { to enable } \\
\text { infusion in space missions } \\
\text { - Adjustments to bandwidth/range } \\
\text { of operation }\end{array}$ & - Low resource, in situ measurements \\
\hline $\begin{array}{l}\text { UV Spectroscopy } \\
\text { (remote) }\end{array}$ & $\begin{array}{l}\text { - Remote observation, } \\
\text { multi-use (ices, isotopes, } \\
\text { surface reflectance) }\end{array}$ & $\begin{array}{l}\text { - Sensitivity and precision } \\
\text { are limited }\end{array}$ & $\begin{array}{l}\cdot \text { Maturation of fine gratings } \\
\cdot \text { Increases in sensitivity }\end{array}$ & $\begin{array}{l}\text { - Medium precision remote } \\
\text { measurements for targeted species }\end{array}$ \\
\hline $\begin{array}{l}\text { Earth-based IR, submm, } \\
\& \text { mm spectroscopy } \\
\text { (ground-based) }\end{array}$ & $\begin{array}{l}\text { - Extremely high spectral } \\
\text { resolution (mm } \\
\text { spectroscopy) } \\
\text { - Flexible and/or rapid } \\
\text { application to targets }\end{array}$ & \begin{tabular}{|l|} 
- Sensitivity and spectral \\
resolution in spectral \\
windows masked by Earth's \\
atmosphere \\
- Sensitivity to restricted \\
atmospheric altitude range \\
prevents bulk atmospheric \\
measurement
\end{tabular} & $\begin{array}{l}\text { - James Webb Space Telescope } \\
\text { - SOFIA } \\
\text { - Continued application of } \\
\text { Atacama Large } \\
\text { Millimeter/submillimeter Array to } \\
\text { planetary targets }\end{array}$ & $\begin{array}{l}\text { - Improved ability to conduct } \\
\text { statistically significant datasets and/or } \\
\text { test for temporal/seasonal effects } \\
\text { beyond the lifetime of a given mission }\end{array}$ \\
\hline Laboratory analyses & $\begin{array}{l}\text { - High precision (sub- } \\
\text { permil) } \\
\text { - Spatial context for some } \\
\text { techniques } \\
\text { - Simultaneous } \\
\text { measurement of multiple } \\
\text { isotopes on given sample } \\
\text { - Archiving ability for future } \\
\text { use }\end{array}$ & $\begin{array}{l}\text { - Mass interferences } \\
\text { - Contamination } \\
\text { - Sample prep }\end{array}$ & $\begin{array}{l}\text { - Improved mass separation, } \\
\text { sample prep, } \\
\text { baking procedures }\end{array}$ & $\begin{array}{l}\text { - Measurement of trace isotopologues } \\
\text { - Lower blanks, enabling } \\
\text { measurement of rare compounds }\end{array}$ \\
\hline
\end{tabular}

\section{Potential Mission Applications}

Prioritization of isotope data for many different mission concepts supports the goals of the science community as a whole (Table 1). Notably, while major patterns and trends will emerge with data from multiple environments (Fig. 1), many of the science questions outlined here can be significantly constrained by a single mission platform. 
Table 4. Possible mission concepts in the coming decade that would be enhanced by the inclusion of isotopic measurements. $M S=$ mass spectrometer, TLS = tunable laser spectrometer.

\begin{tabular}{|c|c|c|c|}
\hline Target & Science Focus for Isotopes Measurement \{Tracing Table 1 Opportunities\} & Modality & Possible instrumentation \\
\hline $\begin{array}{l}\text { Interplanetary } \\
\text { dust }\end{array}$ & Origins (CHON isotopes) $\{1 \mathrm{~A}, 1 \mathrm{D}, 1 \mathrm{E}\}$ & $\begin{array}{l}\text { Dust telescope }(>10 \mathrm{~km} / \mathrm{s} \\
\text { impact) }\end{array}$ & Dust spectrometer [56] \\
\hline Mercury & Origins, evolution of volatiles in end-member chemical environments $\{1 \mathrm{~A}, 2 \mathrm{~A}\}$ & Lander & $\begin{array}{l}\text { MS (volatiles; [57]), Laser-MS, } \\
\text { TLS [58] }\end{array}$ \\
\hline Venus & Origins, interior evolution, atmospheric evolution (noble gases) $\{1 \mathrm{D}, 2 \mathrm{~A}, 3 \mathrm{~B}\}$ & $\begin{array}{l}\text { Direct sampling of atmosphere } \\
\text { and/or surface }\end{array}$ & MS, TLS \\
\hline \multirow{2}{*}{ Mars } & \multirow{2}{*}{ Origins, atmosphere-surface interactions, habitability $\{1 \mathrm{D}, 2 \mathrm{~A}, 3 \mathrm{C}, 3 \mathrm{D} 2,3 \mathrm{D} 3]\}$} & Rover & MS, TLS \\
\hline & & Sample return & Earth-based MS \\
\hline \multirow{2}{*}{ Ceres } & \multirow{2}{*}{$\begin{array}{l}\text { Origin science on volatiles (esp. } H, O, N) \text {, organics evolution }(C, O, N)[59,60] \\
\{1 A, 1 D, 3 A, 3 D 2\}\end{array}$} & Lander & MS, TLS \\
\hline & & Sample return & Earth-based MS \\
\hline $\begin{array}{l}\text { Main belt } \\
\text { comets }\end{array}$ & Origin of volatiles in inner solar system $(\mathrm{H}, \mathrm{O}, \mathrm{N}, \mathrm{C})\{1 \mathrm{D}\}[13]$ & Fly-through, orbiter & MS \\
\hline Europa & $\begin{array}{l}\text { Origins, Habitability (e.g., H, O, C) Prebiotic/exobiology (e.g., C isotopes) } \\
\{1 \mathrm{~A}, 1 \mathrm{~B}, 1 \mathrm{C}, 3 \mathrm{~A}, 3 \mathrm{D} 2\}\end{array}$ & Orbiter, lander & MS \\
\hline \multirow[b]{2}{*}{ lo } & \multirow[b]{2}{*}{ Volcanic processes \& volatile cycling; history of volcanism $\{2 A\}$} & Plume fly-through & MS \\
\hline & & Flyby or orbiter & $\begin{array}{l}\text { UV spectrometer, submm wave } \\
\text { spectrometer }\end{array}$ \\
\hline Saturn & Origin science on volatiles $(\mathrm{H}, \mathrm{O}, \mathrm{N}$, noble gases,etc. $)\{1 \mathrm{~B}\}$ & $\begin{array}{l}\text { Atmospheric probe, ring } \\
\text { skimmer [61] }\end{array}$ & MS, GCMS, TLS \\
\hline Enceladus & Prebiotic/exobiology (e.g., C isotopes) $\{3 \mathrm{~A}, 3 \mathrm{D} 1,3 \mathrm{D} 2,3 \mathrm{D} 3\}$ & $\begin{array}{l}\text { Plume and surface sampling } \\
{[62,63]}\end{array}$ & $\begin{array}{l}\text { Evolved gas analysis via MS or } \\
\text { TLS [64] }\end{array}$ \\
\hline Titan & Origins, atmosphere, evolution, prebiotic chemistry $\{1 \mathrm{~A}, 2 \mathrm{~A}, 3 \mathrm{~A}\}$ & Quadcopter, boat, submarine & GCMS \\
\hline Ice Giants & $\begin{array}{l}\text { Origin science on volatiles ( } \mathrm{He}, \mathrm{Ne}, \mathrm{Ar}, \mathrm{Kr}, \mathrm{Xe} \text {, their isotope ratios, and certain } \\
\left.\text { stable gas isotopes, in particular }{ }^{13} \mathrm{C} / 12 \mathrm{C} \text { and } \mathrm{D} / \mathrm{H} \text {, possibly }{ }^{15 \mathrm{~N} / 14} \mathrm{~N} \text { and }{ }^{34} \mathrm{~S} /{ }^{32} \mathrm{~S}\right) \\
\{1 \mathrm{~B}\}\end{array}$ & $\begin{array}{l}\text { Atmospheric probe down to } \\
>10 \text { bar }\end{array}$ & GCMS [65], TLS \\
\hline Triton & $\begin{array}{l}\left.\text { Origin and evolution via atmosphere composition (e.g., }{ }^{15} \mathrm{~N} /{ }^{14} \mathrm{~N}\right) \text { or ionosphere } \\
\{2 \mathrm{~A}, 3 \mathrm{~A}\}\end{array}$ & $\begin{array}{l}\text { Atmosphere (remote, fly- } \\
\text { through), ionosphere (fly- } \\
\text { through) or lander }\end{array}$ & $\begin{array}{l}\text { UV spectrometer, GCMS, } \\
\text { plasma spectrometer }\end{array}$ \\
\hline Pluto & Origin and evolution via atmosphere composition (e.g., $\left.{ }^{15 N} \mathrm{~N} / 14 \mathrm{~N}\right)\{2 \mathrm{~A}, 3 \mathrm{~A}\}$ & Orbiter & $\begin{array}{l}\text { UV spectrometer, submm wave } \\
\text { spectrometer }\end{array}$ \\
\hline \multirow[b]{2}{*}{ Comet } & \multirow[b]{2}{*}{ Solar system origins and evolution $\{1 \mathrm{~A}, 3 \mathrm{~A}\}$} & Sample return (short-period) & Earth-based MS \\
\hline & & $\begin{array}{l}\text { Remote (e.g., smallsat flyby) } \\
\text { (short- and long- period) }\end{array}$ & Submm wave spectrometer [66] \\
\hline
\end{tabular}

References (PSDS WP = Planetary Science Decadal Survey White Paper; PMCS = Planetary Mission Concept Study) • [1] Hoefs (2018) Stable isotope geochemistry [2] Clayton et al. (1973) Science, 182 [3] Clayton et al. (1977) EPSL, 34 [4] Mandt et al. (2014) ApJL, 788 [5] Mousis et al. (2009) Icarus, 204 [6] Clark et al. (2019) Icarus, 321 [7] Neveu et al. (2020) Icarus, 345 [8] Hoppe et al. (2018) Space Sci Rev, 214 [9] Altwegg et al. (2015) Science, 347 [10] Donahue et al. (1982) Science, 216 [11] Bertaux et al. (2007) Nature, 450 [12] Greenwood and Anand (2020) Space Sci Rev, 216 [13] Landis et al. (2020) PSDS WP [14] Jakosky et al. (2018) Icarus, 315 [15] Mahaffy et al. (2013) Science 341 [16] Atreya et al. (2013) GRL 40 [17] Wong et al. (2013) GRL 40 [18] Kite and Melwani Daswani (2019) EPSL, 524 [19] Cohen et al. (2020) PSDS PMCS [20] Verdier-Paoletti et al. (2017) EPSL, 458 [21] Clayton and Mayeda (1999) GCA, 63 [22] Benedix et al. (2003) GCA, 67 [23] Thiemens and Heidenreich (1983) Science 219 [24] Farquhar et al. (2000) Science 289 [25] Franz et al. (2014) Nature 508 [26] Grassineau et al. (2006) [27] Milkov and Etiope (2018) Org Geochem, 125 [28] Schidlowski (2001) Precambrian Res 106 [29]

Canfield and Thamdrup (1994) Science, 266 [30] Canfield (2001) Rev Mineral Geochem, 43 [31] Sim et al. (2011) Geochim Cosmochim Ac, 75 [32] Wing and Halevy (2014) PNAS, 111 [33] Farquhar et al. (2001) JGR Planets, 106 [34] Farquhar et al. (2013) PNAS, 110 [35] Shields and Vezier (2002) Geochem Geophy Geosy, 3 [36] Franz et al. (2017) Nature Geoscience, 10 [37] Theiling and Coleman (2019) Mar Geol, 413 [38] Brockwell et al. (2016) IEEE Aerospace Conference [39] Drouin et al. (2016) J Chem Phys, 145 [40] Biver et al. (2019) $\underline{A \& A, 630}$ [41] Hartogh et al. (2011) Nature, 478 [42] Lis et al. (2019) $A \& A, 625$ [43] Korablev et al. (2019) Nature, 568 [44] Harlander and Roesler (1990) Proc. SPIE, 1235 [45] Hosseini (2019) Appl Opt, 58 [46] Chakrabarti et al. (1994) Appl Opt, 33 [47] Harlander et al. (1992) ApJ, 396 [48] Englert et al. (2010) JGR Atmospheres, 115 [49] Englert et al. (2008) GRL, 35 [50] Harlander et al. (2017) Space Sci Rev, 212 [51] Serigano et al. (2016) ApJL 821 [52] Villanueva et al. (2015) Science, 348 [53] Hattori et al. (2011) J Agr Food Chem, 59 [54] Eiler et al. (2017) Int J Mass Spectrom, 422 [55] Heck (2014) M\&PS, 49 [56] Horányi et al. (2020) PSDS WP [57] Deutsch et al. (2020) PSDS WP [58] Vander Kaaden et al. (2020) PSDS WP [59] Castillo-Rogez et al. (2020) PMCS [60] Castillo-Rogez et al. (2020) PSDS WP [61] Tiscareno et al. (2020) PSDS WP [62] Choukroun et al. (2020) PSDS WP [63] Cable et al. (2020) PSDS WP [64] MacKenzie et al. (2020) PMCS [65] Ice Giants Pre-Decadal Study Final Report [66] Lis et al. (2020) PSDS WP 